\title{
Transformational Leadership and Digital Skills in Higher Education Institutes: During the COVID-19 Pandemic
}

\author{
Hera Antonopoulou ${ }^{1}$, Constantinos Halkiopoulos ${ }^{1 *}$, Olympia Barlou ${ }^{2}$, \\ Grigorios N. Beligiannis ${ }^{2}$ \\ ${ }^{1}$ Department of Management Science and Technology, University of Patras, Patras, Greece \\ ${ }^{2}$ Department of Business Administration of Food \& Agricultural Enterprises, University of Patras, Patras, Greece
}

\begin{abstract}
Objectives: Recently, due to special conditions that the global community is experiencing (Covid19), there is growing interest in research in educational leadership, especially in higher education, which will create an environment embedded in a collaborative culture, open to improvements, testing, and often unexpected challenges. Among the different forms of educational leadership, transformational leadership is recognized as the most appropriate for application in higher education, as it focuses on the division of leadership among academics with different skills in order to manage in a collective way the range of leadership duties required in different contexts Methods/Analysis: This view is also reflected in this research paper, which focused on the degree of three specific forms of leadership (transformational leadership, transactional leadership, and leadership to be avoided) by members of the Senate of the University of Peloponnese. Descriptive and inductive methods of statistical analyses were applied for the interpretation of results. Findings: Notably, the findings indicate that leadership outcome has a strong positive correlation with transformational leadership and negative correlation with passive-to avoid leadership, confirming that higher transformational leadership implies greater efficiency and satisfaction for employees. Novelty/Improvement: A high degree of passive leadership coexists with the corresponding negative degree of implementation of digital leadership.
\end{abstract}

Keywords:

Educational Leadership;

ICT;

Higher Education;

E-skills;

Behavioral Data Analysis.

Article History:

Received: 09 November 2020

Revised: $\quad 13$ January 2021

Accepted: $\quad 20$ January 2021

Published: $01 \quad$ February 2021

\section{1- Introduction}

Digital technology has changed organizations, especially teachers, in an irreversible way. Digitization is transforming organizations, work environment, and processes, creating new challenges that must be addressed by leaders. The latest findings of a Eurobarometer survey show that most respondents believe that Digitization has a positive impact on the economy $(75 \%)$, quality of life $(67 \%)$, and society $(64 \%)$. Indeed, in the last decade, the daily lives of people and the operation of businesses have been greatly transformed by digital technologies [1]. The digital transformation of an organization mainly refers to the adoption of a portfolio of technologies such as the Internet of Things (IoT), digital platforms, social media, Artificial Intelligence (AI), Machine Learning (ML), and Big Data. At the macro level, the transition to modern technologies defines new competition mechanisms, structures, new work systems, and interactions that may emerge. At the micro-level, digitization affects the dynamics of organizations, their processes, and the required new skills of their employees from the highest to the lowest levels [2]. Based on the above, it seems that leaders are key pillars in the development of a digital culture of a modern organization [3].

* CONTACT: Halkion@upatras.gr

DOI: http://dx.doi.org/10.28991/esj-2021-01252

(C) 2021 by the authors. Licensee ESJ, Italy. This is an open access article under the terms and conditions of the Creative Commons Attribution (CC-BY) license (https://creativecommons.org/licenses/by/4.0/). 
In Higher Education Institutions, leadership and leadership style play an important role in order to have a robust institution. It is reasonable that the leadership style followed by the Head of the educational institution does not create the feeling of oppression and the imposition of force on the lower-level academics and on the administrative and other staff of the Foundation $[4,5]$.

Research on leadership in education has demonstrated the role and importance of the leader in the improvement and effectiveness of the Foundation. The same research presented evidence that reinforces the view that leadership is a multilevel concept and that it can influence parameters that affect educational organizations and students. The Pandemic with COVID19 that still affects global communities highlighted even more urgently the need that educational leaders and the academic community at all levels ought to possess digital skills [5]. Today more than ever the importance of the digital leader has emerged, since without them the process of the digital transition that was applied in the universities of Greece could not be implemented in order to complete smoothly the educational process. In the current era of pandemic crisis, the more digital skills possessed by an Academic Leader of the Senate, the more "strongly" an academic institution can be adapted in the new Digital Reality.

The present study highlights the importance of leadership through a detailed description of the purpose and role it plays in the educational process, the basic leadership types, and their effectiveness when applied in educational settings of higher education. Then, through the separate analysis of digital transformation and other leadership types, the leadership characteristics required for the digital age in the academic community are described and the most effective type of management of a higher education institution is highlighted.

\section{2- Literature Review}

\section{2-1- Concept}

The leadership role is considered as a crucial parameter in educational institutions. Leaders' mission is to guide and lead individuals in the right direction. In this way, they can fulfill their educational duties in a satisfactory manner, can correspond better to challenges, and overcome obstacles.

According to several relevant research papers, but also the lessons of common experience, a critical factor of organizational efficiency and success is the management and leadership of an organization or service of any kind in the public or private sector. Every manager, to function effectively, exercises (or is influenced by) leadership and the way it is organized and expressed in a specific context and environment. According to many theorists of organizational and administrative science, the principles of administration are widely applied in education, so that educational administration is the main testing ground for relevant principles and practices [6]. It is not surprising, then, that the question of leadership occupies scientific research in educational administration and is at the heart of many modern educational systems.

The discussion about the education management system in our country can be considered as part of the general reflection on the Greek administrative system. In the management of all kinds of organizations, modern developments and persistent, complex, and interrelated problems increase the pressures for balancing or compromising between differentiation and cohesion [7]. The role of those in charge is rearranged and leadership emerges as a critical parameter of the effectiveness of general administrative behavior. In Greece, the current administration system is under review, and its role of educational director or "leader" under constant challenge and transformation.

\section{2-2- Leadership Outcome}

Leadership style in an organization (transformative/operational) is related to the success of the team as a whole. The three elements that make up a leadership outcome are the degree to which raters feel that their leader motivates them (Extra effort), the effectiveness with which they perceive their leader interact at different organizational levels. (Effectiveness) and the degree of satisfaction they derive from their leader's working methods, in relation to others (Satisfaction with the Leadership) [8].

It is worth noting at this point that extra effort motivates others to do more than they thought they would do, increases the desire of others to succeed, and finally increases the desire of others to work harder. Effectiveness is also answered by the leader as feedback to himself as to whether it is effective in meeting the work-related needs of others, whether is effective in representing the team in higher organizational levels as well as in leading a team that is effective. Finally, satisfaction from leadership is related to the use of appropriate leadership methods and with good and fruitful cooperation with others $[9,10]$.

In conclusion, research based on the Multi-factor Leadership Questionnaire developed by Bass et al. have shown that employees who give high scores to their leaders in transformational components also rate them as highly efficient, as opposed to those who score high in trading components and are considered less efficient $[11,12]$. 


\section{2-3- Leadership in Academic Society}

According to current research, the academic community faces challenges similar to any other organization with an urgent need for effective development of academic leadership, which is critical to the smooth running and optimal success of an academic institution's long-term goals. Academic transformational leaders seem to be able to manage a university institution in a more effective way, leading the organization to maximize its organizational results [13].

Research on leadership in education has demonstrated the role and importance of the leader in the improvement and effectiveness of the foundation. The same research presented evidence that reinforces the view that leadership is a multilevel concept and that it can influence variables that affect educational organizations and students [14, 15].

In higher educational institutions, academics are vested with the authority and responsibility of even making provision of opportunities to students in order to ameliorate their teaching and leadership skills. Occasionally students, pursuing masters or doctoral programs are provided with the opportunities to even give lectures in the absence of professors. Hence, in this way, students are able to develop their skills in terms of teaching, leadership, monitoring, and supervision via traditional methods with direct communication or distance-learning assets for instance webinars [16].

\section{2-4- Integration of ICTs in Educational Leadership}

The development of ICT in organizations, and especially in educational organizations, is linked to effective use of innovative opportunities presented at intervals, which presuppose the existence of digital leadership skills by the staff that works in them and it is considered as a crucial point to illustrate the profile of digital leader [17].

During pandemic (COVID-19), the need for the acquisition of digital skills by educational leaders and teachers in general at all levels is even more urgent. Today, more than ever, the importance of digital leaders has emerged, since, without them, the process of the digital transition that was applied in the Higher Education Institutions of Greece could not be implemented in order to complete the educational process without obstacles.

\section{2-5- Digital Leadership}

Digital leadership is the strategic use of an organization's digital data to achieve business goals. Digital leadership can be applied both in an organizational and individual level. Businesses, like universities, need to transform their practices and continue to adapt in order to be effective in the age of the Internet. In this light, it is necessary to present the digital skills that characterize a leader. In the present work, it is found that the high degree of transformational leadership coexists with the high degree of implementation of digital leadership in Higher Education [18]. The following are research hypotheses that have led us to explore the relationship between digital skills and the type of leadership that can contribute to the digital transformation of an academic institution in an optimal way, in order to identify new findings and suggest future implications for this research.

Based on previous research in academic institutions, it has been shown that transformational leadership has a positive and statistically significant effect $(\mathrm{p}=0.034)$ on digital leadership. Transactional and Passive Leadership, which do not seem to have a statistically significant impact on the degree of Digital Leadership [19]. Also, the high number of declared digital properties showed high levels of efficiency and satisfaction from leadership training [19]. In addition, in recent research, leadership outcome seems to have a positive and statistically significant effect $(\mathrm{p}=0.014)$ on digital leadership, that is, the greater the effectiveness and satisfaction of the leadership, the greater the degree of Digital leadership practice [20].

It is worth mentioning that the definition of digital leadership and digital leader is not completely clear. Others consider the digital leader as the leader of a digital business - Organization and others, similar to the scope of this paper that the leader who has specific digital skills (digital knowledge) along with business and strategic knowledge.

In our model, the digital leader is characterized by the following triptych (www.eskills-lead.eu):

- Strategic leadership: Mentoring interdisciplinary staff and influencing cross-border actors (operational, geographical);

- Business knowledge: Innovative business and operational models, which add value to Educational organizations;

- Digital knowledge: Visioning and implementation of changes to enhance the performance of the Educational Institution, exploiting technological trends as opportunities for innovation, digital skills.

\section{2-6- Transformational Leadership}

This style of leadership is often associated with vision, the establishment of guidelines for the restructuring and realigning of an organization, development of working staff, and involvement with the external community via publicity and networking actions $[21,22]$. 
An effective form of leadership that seems to promote in an optimal way digital innovation is transformational leadership. The leader of transformational leadership aims to motivate followers, seek to meet their highest needs, and commit their full commitment. Transformational leadership, which is associated with charisma and vision, emerges as the most appropriate model, as it by definition focuses on issues of change and transformation [23, 24].

Much of what has been discovered about such leadership in this body of research reinforces the validity of some core sets of leadership practices. The creation of vision and the establishment of guidelines and goal directions can motivate leaders' colleagues in a way that they have a shared purpose as a vital stimulant for their work. Shared vision via the implementation of group goals is correlated with high-performance expectations [25]. The aspect of the development of staff has a significant contribution to motivation and the principal purpose of this is not only to promote the skills and the knowledge of academics and other staff in order to accomplish organizational goals but also the predisposition to persist in fulfilling these goals as personal traits such as commitment, capacity, and resilience [26]. Some of these practices refer to individualized support, intellectual stimulation, and modelling suitable values and behavioural patterns. These specific practices combine both functional assets from managerial taxonomy like support, development, mentoring, recognition, and rewards and also personal assets like acknowledging and providing feedback to good work and active listening. According to recent research, successful transformational leaders evaluate and promote the personal and professional welfare of their colleagues [27]. Another aspect of transformational leadership has to do with the reconstructing of an organization as far as work conditions is concerned. Specific practices such as establishing a collaborative culture with productive relations between academics, colleagues, students, and connection of educational environments with the wider community [28]. Other practices in the managerial taxonomy include managing conflict and group building, delegating, consulting, and networking.

\section{3- Research Methodology}

\section{3-1- Research Questions}

Considering the importance of Leadership and digital skills must be in possession of a modern leader and given the transformation of society, this research aims to detect the types of leadership associated with digital skills and their relationship with digital leadership. Therefore, based on what has been reported so far, and guided by the current literature, the research questions to be investigated can be summarized as follows:

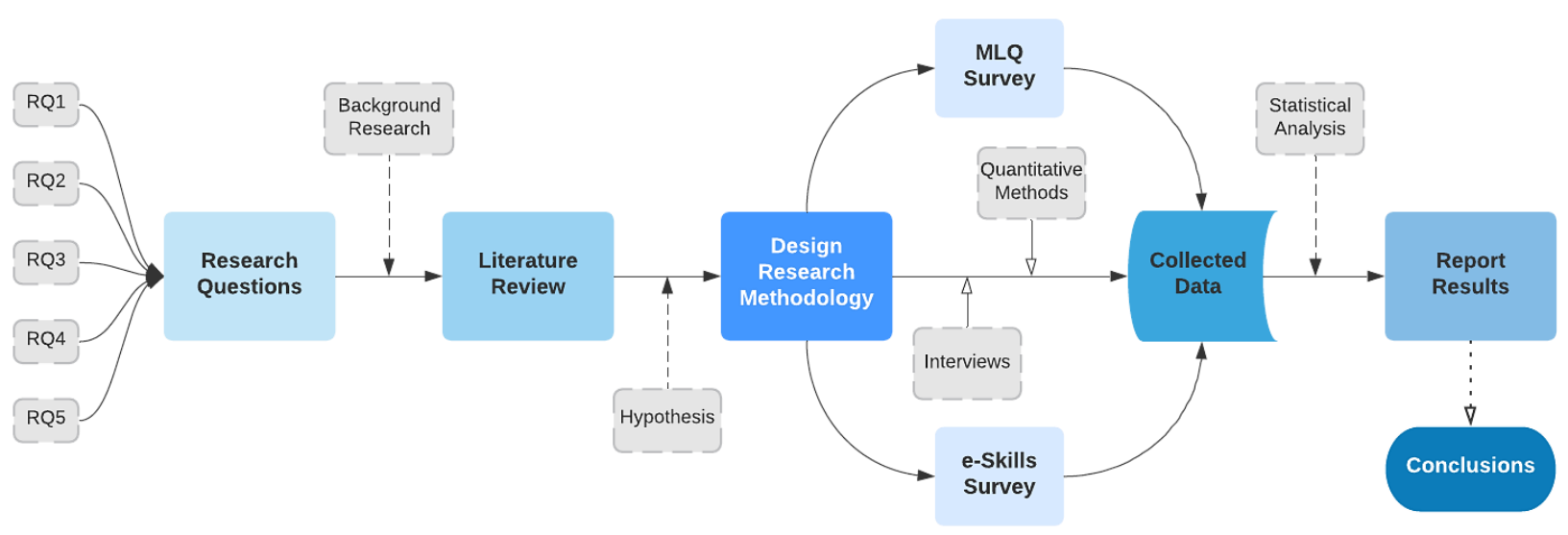

Figure 1. Flowchart of Research Methodology.

- [RQ1] What leadership type is emerging?

- [RQ2] Do leadership types and results vary depending on the leader's gender, years of service overall, and / or managerial position?

- [RQ3] Is the application of a particular leadership type related to the knowledge of specific digital skills?

- [RQ4] Possible relationship of digital leadership with leadership types

- [RQ5] Is the subject field (Humanities and Social Sciences Direction / Natural and Applied Sciences Direction) related to the presence of digital leaders?

\section{3-2- Data Collection Tools}

To answer the research questions of this paper, the protocol used for quantitative research was followed, which consists of searching and using the modern literature to identify research questions, collect scientific data through the 
use of scales containing relevant questions with a defined and measurable range of answers and, finally, the analysis of this data using statistical scientific methods [29].

For the above reason, in the present research study, two questionnaires were used, which were administered to the members of the senate of the University of the Peloponnese in Greece. The first questionnaire was the Multifactor Leadership Questionnaire (MLQ) and the second questionnaire consisted of e-skills questions, which according to the European Union study «E-Leadership: Skills for Competitiveness and Innovation. A particular focus of the study was on «High-Tech Leadership Skills for Europe» transforming a leader into a digital leader. E-Leaders are both business and digitally savvy and exhibit a capability to lead strategically. They might be ICT leaders who are also business-savvy or business leaders who are digitally-savvy. E-leadership involves leading and managing e-skilled professionals as well as other professionals [30].

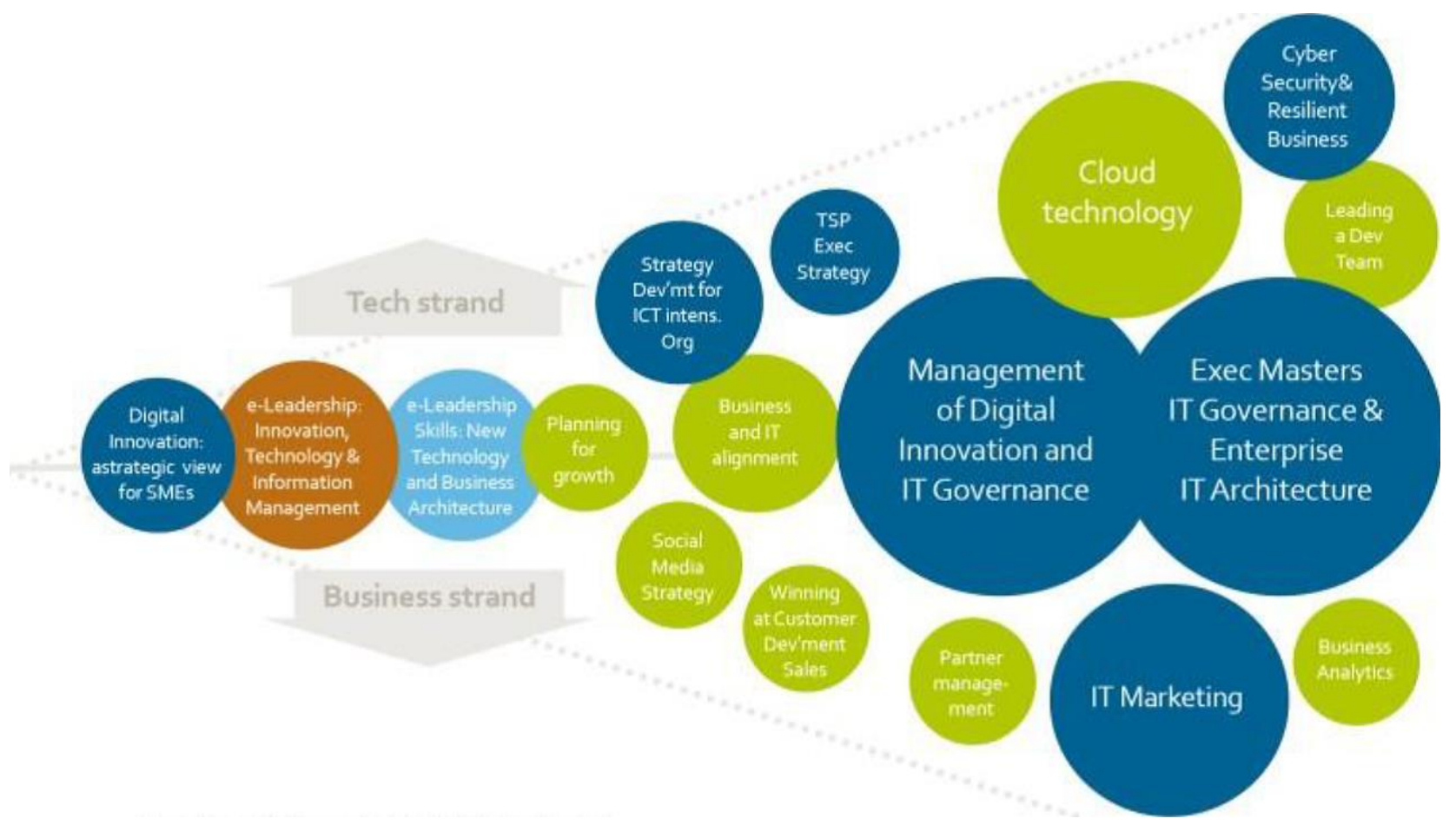

Figure 2. The e-Leadership journey as a framework for e-leadership business demand and education and training offers.

The first questionnaire is a measure of the leadership style. The Multifactor Leadership Questionnaire was used Leadership Questionnaire (MLQ) and more specifically the MLQ Form (Form 5X Short) developed by Bass and Avolio (2004). That particular one formula, MLQ (5X-Short), according to Avolio \& Bass (2004), is structured from 45 questions, of which 36 explore the 9 leadership components included in Full Range Leadership (FRL) - (4 questions/leaderboard), namely: (i) Transformational (5 Leadership Ingredients) (ii) Transactional (Contingent Reward \& Management by Exception-Active) - (2 Lead Components) (iii) Passive-Avoiding Leadership (Management by Exception - Passive \& Avoidant/Laissez-Faire Leadership) - (2 Leadership Ingredients) Also, the remaining 9 questions of this scale explore the leadership outcomes:

- Extra effort - (3 questions)

- Effectiveness - (4 questions)

- Satisfaction with the leadership - (2 questions)

The measurement and evaluation of the above nine leading factors, such as and the outcome of leadership is made by appropriately matching - utilizing 45 total questions that make up the MLQ (5X-Short).

Respondents were asked to rate the extent to which they exhibited specific behaviors, on a Likert-type scale from 1 (Not at all) to 5 (Almost always) by answering 45 questions. Digital leadership was similarly measured, using 5 related questions. For each respondent, the average of the answers for each leadership style is calculated and an individual average score can range from 1 - 5. The higher the score, the more the respondent exercises that leadership style.

The application of the questionnaires to members of the Senate of the University of the Peloponnese was implemented through a unique completion link through Google's Google Form application. The information to be collected will be coded and analysed using a statistical program (SPSS 21). The comparison of demographic-descriptive data will be done either by spreading analysis or by Pearson's $\mathrm{X}^{2}$ analysis. The correlation between the variables will be done with regression analysis. 


\section{3-3- Measures and Data Analysis}

In the data analysis phase, the data collected from the questionnaires were pre-processed and coded and entered into a database of the statistical software SPSS 21. Different methods of statistical analysis, both descriptive and inductive, are used for each category of variables. Specifically, for the categorical variables (demographic characteristics, digital properties) were used:

- Descriptive methods: Frequency tables - percentages, percentage bar charts, and pie charts;

- Inductive methods: Fisher's exact test to investigate a possible relationship between two categorical variables.

For the operative variables (leadership type, leadership outcome, number of digital skills) were used:

- Descriptive methods: minimum value, maximum value, mean value, standard deviation, averages bar graphs;

- Inductive methods: Non-parametric Mann-Whitney test statistics (for comparing the means of two independent samples) and Wilcoxon Signed Ranks Test (for comparing the means of two related samples).

The possible correlation between the various ordinal variables was investigated using the Pearson linear correlation coefficient. Also, the possible dependence between the different operative variables was investigated through simple linear regression.

The reliability of the various scales of questions regarding leadership types and leadership outcome was measured with Cronbach's Alpha Credibility Index. Values of the index above 0.7 (or above 0.6 according to various researchers) indicate satisfactory reliability. For all hypothesis tests of statistical tests, correlations, and linear regressions, a significance level $\alpha=0.05$ were used.

\section{4- Results and Discussion}

\section{4-1- Demographic Characteristics}

Through descriptive statistics, we find the following: The majority of participants in the survey were men $80.0 \%$ $(\mathrm{N}=16)$, while $20.0 \%$ were women $(\mathrm{N}=4)$ (Figure 3$)$. As members of the senate, $40.0 \%$ of respondents $(\mathrm{N}=8)$ belonged to the age category of $60+$ years and $55.5 \%(\mathrm{~N}=11)$ were 51-60 years old. However, there was a 5.0\% $(\mathrm{N}=1)$ percentage in the 41-50 age category (Figure 3). The sample members had several years of service in higher education, with $50.0 \%$ $(\mathrm{N}=10)$ serving more than 20 years (Figure 4$)$.
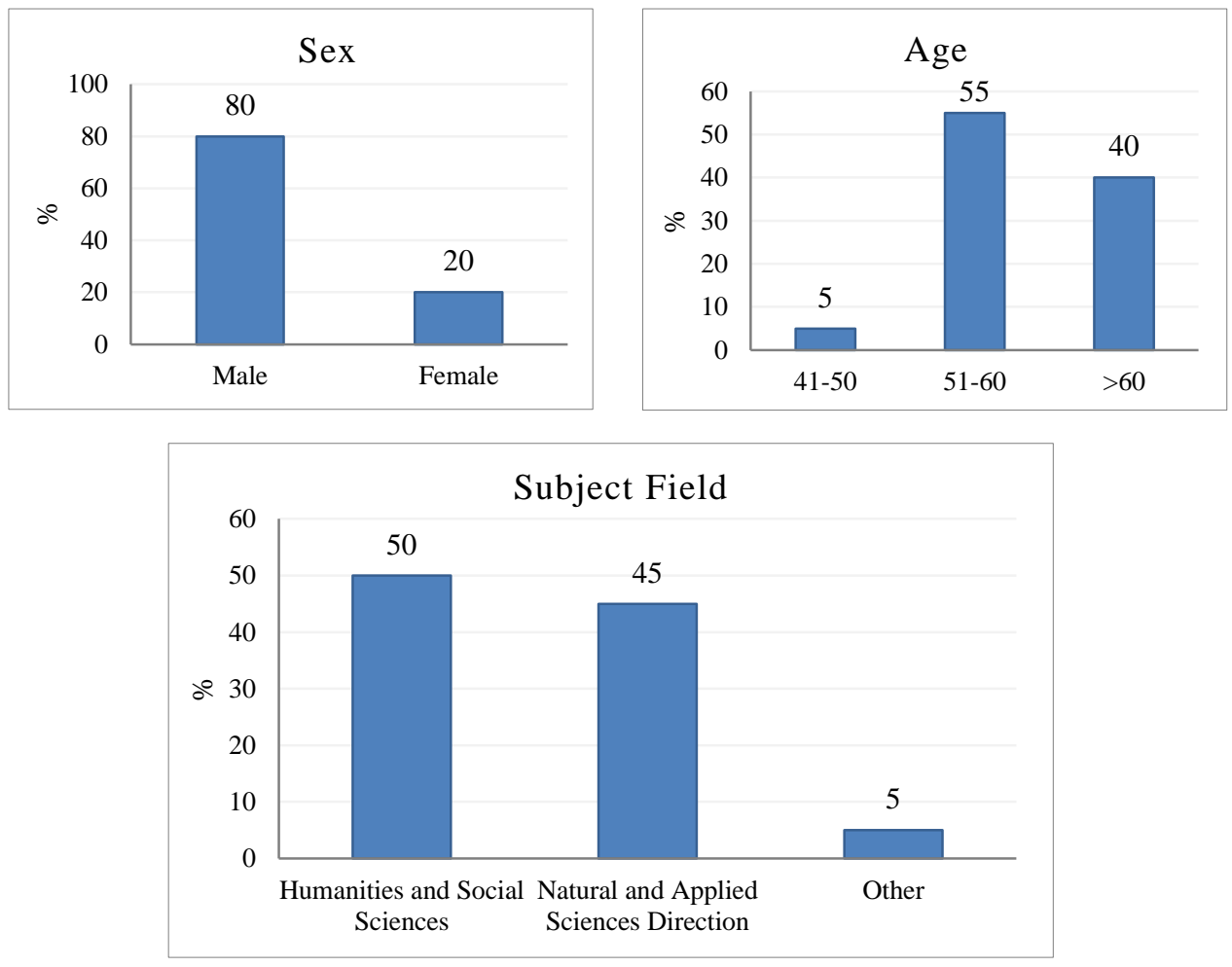

Figure 3. Descriptive Statistics of the Sample.

Also, $60.0 \%(\mathrm{~N}=12)$ have been in management positions for more than 9 years (Figure 4). Finally, most participants, $50.0 \%(\mathrm{~N}=10)$, came from the theoretical direction and $45.0 \%$ came from the positive direction (N=9) (Figure 3). Table 1 shows the above descriptive statistics of the sample of the present research. 

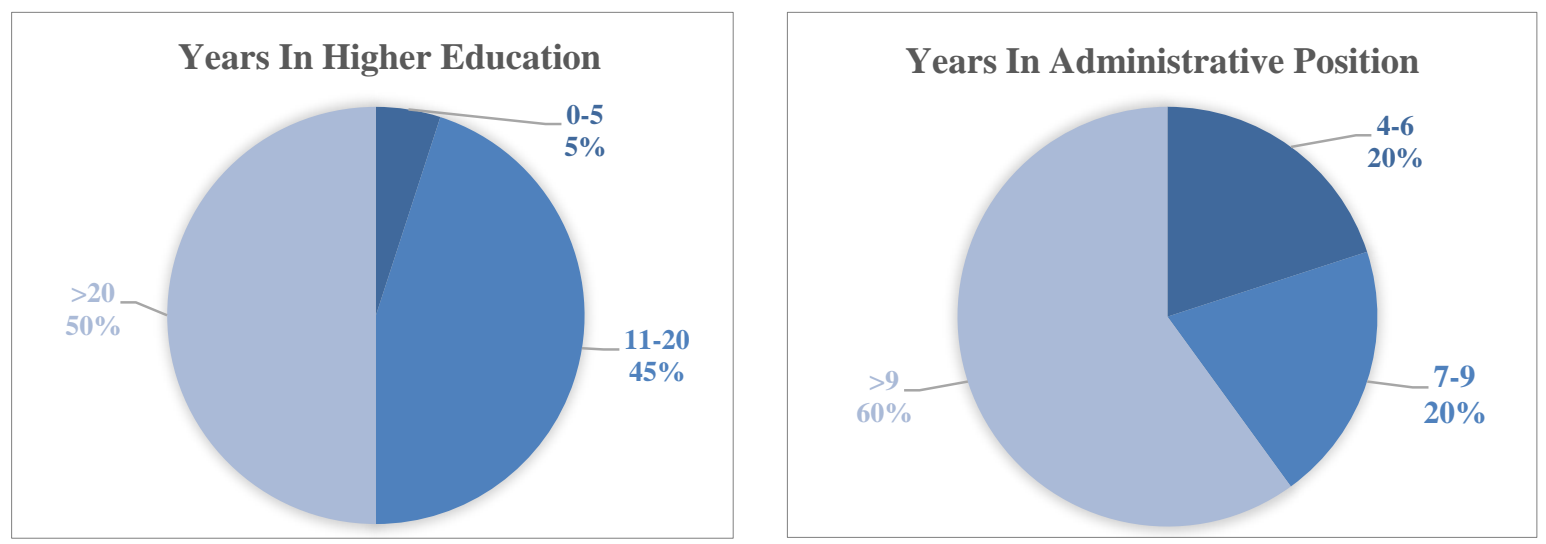

Figure 4. Years of Service in Higher / Administrative Positions.

Table 1. Demographic characteristics $(\mathrm{N}=\mathbf{2 0})$.

\begin{tabular}{cccc}
\hline Demographic characteristics & Frequency (N) & \multicolumn{2}{c}{ Percentage (\%) } \\
\hline Sex & Male & 16 & 80.0 \\
& Female & 4 & 20.0 \\
\hline \multirow{2}{*}{ Age } & $41-50$ & 1 & 5.0 \\
& $51-60$ & 11 & 55.0 \\
& $>60$ & 8 & 40.0 \\
\hline \multirow{3}{*}{ Years of Service in Higher Education } & $0-5$ & 1 & 5.0 \\
& $11-20$ & 9 & 45.0 \\
\hline \multirow{2}{*}{ Years of Service in Administrative } & $>20$ & 10 & 50.0 \\
\hline Position & $4-6$ & 4 & 20.0 \\
& $7-9$ & 4 & 20.0 \\
& Humanities and Social Sciences Direction & 10 & 50.0 \\
Subject Field & Natural and Applied Sciences Direction & 9 & 45.0 \\
& Other & 1 & 5.0 \\
\hline
\end{tabular}

\section{4-2- Overview of Leadership Types}

Regarding the MLQ questionnaire, the reliability of all scales is satisfactory since Cronbach's Alpha has values from 0.522 (in the case of Leadership Outcome) to 0.856 (in the case of Passive Leadership). Especially in the case of digital leadership, Cronbach's Alpha stands at 0.731 . This fact allows us to consider that the 5 questions that measure this particular leadership style belong to the same conceptual unit and can be represented by a new variable, as the average of these 5 questions (Table 2).

Table 2. Examined variables.

\begin{tabular}{lcccccc}
\hline \multicolumn{1}{c}{ Leadership Types } & N & Min & Max & Mean & SD & Cronbach's Alpha \\
\hline Transformational leadership & 20 & 3.47 & 4.40 & 4.09 & 0.30 & $0.740^{*}$ \\
Transactional leadership & 20 & 2.25 & 4.50 & 3.66 & 0.66 & 0.764 \\
Passive to avoid leadership & 20 & 1.00 & 2.20 & 1.43 & 0.50 & $0.856^{* *}$ \\
Outcome leadership & 20 & 3.56 & 4.67 & 4.02 & 0.27 & 0.522 \\
Digital leadership & 20 & 3.20 & 5.00 & 4.18 & 0.52 & 0.731 \\
\hline
\end{tabular}

* Excluded questions $21.23,26,2,19$ which were found to be negatively correlated with the other questions for the specific style of Leadership.

**Excluded were questions 3, 7 and 33 which were found to be negatively correlated with the other questions for specific leadership style. 


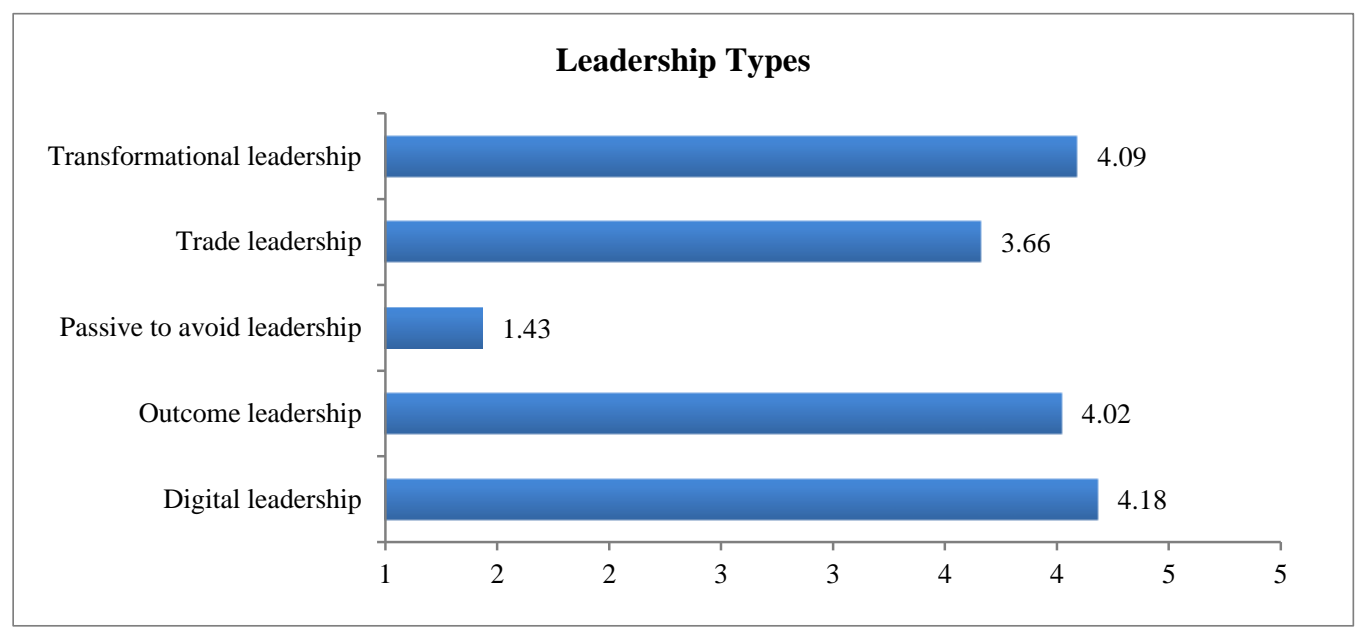

Figure 5. Levels of examined variables.

Based on the analysis we performed, we found that the respondents exercise to a great extent Transformational leadership (Mean 4.09) but also Transactional leadership (Mean 3.66) with a slightly lower frequency. The difference in the degree of exercise of these two leadership types is statistically significant ( $\mathrm{p}<0.05)$ (Figure 5). In contrast to the above, we observed that the participants in the research avoided exercising Passive - To avoid leadership (Mean 1.43). In fact, this style is practiced to a statistically significantly lower degree in relation to both Transformational and Transactional leadership ( $\mathrm{p}<0.05$ ) (Table 3).

Table 3. Differences between leadership types.

\begin{tabular}{|c|c|c|c|c|}
\hline Leadership Types & Mean & SD & Test & P-value \\
\hline Transformational leadership & 4.09 & 0.30 & \multirow{2}{*}{ Wilkoxon Signed Ranks Test } & \multirow{2}{*}{$0.002^{* *}$} \\
\hline Transactional leadership & 3.66 & 0.66 & & \\
\hline Transformational leadership & 4.09 & 0.30 & \multirow{2}{*}{ Wilkoxon Signed Ranks Test } & \multirow{2}{*}{$0.000^{* *} *$} \\
\hline Passive to avoid leadership & 1.43 & 0.50 & & \\
\hline Transactional leadership & 3.66 & 0.66 & \multirow{2}{*}{ Wilkoxon Signed Ranks Test } & \multirow{2}{*}{$0.000 * *$} \\
\hline Passive to avoid leadership & 1.43 & 0.50 & & \\
\hline
\end{tabular}

** Correlation is statistically significant at level 0.01

In addition, the mean 4.02 in Leadership Outcome shows great efficiency and satisfaction from the leadership style followed, while it seems that the respondents exercised to a large extent Digital Leadership (Mean 4.18).

\section{4-3- Demographic Based Leadership Types}

In order to determine whether demographic characteristics have a statistically significant effect on the leadership style exercised, non-parametric Mann-Whitney statistical tests were performed.

Table 4. Leadership types per Sex.

\begin{tabular}{|c|c|c|c|c|c|}
\hline Leadership Types & Sex & Mean & SD & Test & P-value \\
\hline \multirow{2}{*}{ Transformational leadership } & Male & 4.15 & 0.28 & \multirow{2}{*}{ Mann-Whitney } & \multirow{2}{*}{0.122} \\
\hline & Female & 3.88 & 0.32 & & \\
\hline \multirow{2}{*}{ Transactional leadership } & Male & 3.79 & 0.49 & \multirow{2}{*}{ Mann-Whitney } & \multirow{2}{*}{0.290} \\
\hline & Female & 3.13 & 1.05 & & \\
\hline \multirow{2}{*}{ Passive to avoid leadership } & Male & 1.43 & 0.55 & \multirow{2}{*}{ Mann-Whitney } & \multirow{2}{*}{0.554} \\
\hline & Female & 1.45 & 0.30 & & \\
\hline \multirow{2}{*}{ Outcome leadership } & Male & 4.03 & 0.21 & \multirow{2}{*}{ Mann-Whitney } & \multirow{2}{*}{0.335} \\
\hline & Female & 3.94 & 0.50 & & \\
\hline \multirow{2}{*}{ Digital leadership } & Male & 4.40 & 0.29 & \multirow{2}{*}{ Mann-Whitney } & \multirow{2}{*}{$0.000 * *$} \\
\hline & Female & 3.30 & 0.12 & & \\
\hline
\end{tabular}

** Correlation is statistically significant at level 0.01

Initially, we found that gender did not affect the degree to which each leadership style was exercised by members of the Senate who participated in the survey. Male respondents exercise more Transformational leadership and Transactional leadership than women, but the differences are not statistically significant ( $p>0.05)$. In contrast, male participants appeared to apply statistically significantly more than women, digital leadership ( $p<0.05)$ (Table 4$)$. 
Table 5. Leadership types per Age.

\begin{tabular}{|c|c|c|c|c|c|}
\hline Leadership Types & Age & Mean & SD & Test & P-value \\
\hline \multirow{2}{*}{ Transformational leadership } & $\leq 60$ & 4.03 & 0.29 & \multirow{2}{*}{ Mann-Whitney } & \multirow{2}{*}{0.343} \\
\hline & $>60$ & 4.18 & 0.31 & & \\
\hline \multirow{2}{*}{ Transactional leadership } & $\leq 60$ & 3.61 & 0.51 & \multirow{2}{*}{ Mann-Whitney } & \multirow{2}{*}{0.384} \\
\hline & $>60$ & 3.72 & 0.88 & & \\
\hline \multirow{2}{*}{ Passive to avoid leadership } & $\leq 60$ & 1.60 & 0.55 & \multirow{2}{*}{ Mann-Whitney } & \multirow{2}{*}{0.208} \\
\hline & $>60$ & 1.18 & 0.27 & & \\
\hline \multirow{2}{*}{ Outcome leadership } & $\leq 60$ & 4.01 & 0.27 & \multirow{2}{*}{ Mann-Whitney } & \multirow{2}{*}{1.000} \\
\hline & $>60$ & 4.03 & 0.29 & & \\
\hline \multirow{2}{*}{ Digital leadership } & $\leq 60$ & 4.40 & 0.40 & \multirow{2}{*}{ Mann-Whitney } & \multirow{2}{*}{$0.012 *$} \\
\hline & $>60$ & 3.85 & 0.53 & & \\
\hline
\end{tabular}

* Correlation is statistically significant at level 0.05

In addition, we found that age also has a statistically significant effect on digital leadership, since participants under the age of 60 apply it statistically significantly more than those over the age of 60 ( $p<0.05)$ (Table 5).

Table 6. Leadership Types per Years of Service in Higher Education.

\begin{tabular}{|c|c|c|c|c|c|}
\hline Leadership Types & Years of Serv. & Mean & SD & Test & P-value \\
\hline \multirow{2}{*}{ Transformational leadership } & $\leq 20$ & 4.25 & 0.22 & \multirow{2}{*}{ Mann-Whitney } & \multirow{2}{*}{$0.009 * *$} \\
\hline & $>20$ & 3.94 & 0.29 & & \\
\hline \multirow{2}{*}{ Transactional leadership } & $\leq 20$ & 3.99 & 0.27 & \multirow{2}{*}{ Mann-Whitney } & \multirow{2}{*}{0.063} \\
\hline & $>20$ & 3.33 & 0.78 & & \\
\hline \multirow{2}{*}{ Passive to avoid leadership } & $\leq 20$ & 1.20 & 0.40 & \multirow{2}{*}{ Mann-Whitney } & \multirow{2}{*}{$0.043^{*}$} \\
\hline & $>20$ & 1.66 & 0.50 & & \\
\hline \multirow{2}{*}{ Outcome leadership } & $\leq 20$ & 4.04 & 0.25 & \multirow{2}{*}{ Mann-Whitney } & \multirow{2}{*}{0.436} \\
\hline & $>20$ & 3.99 & 0.31 & & \\
\hline \multirow{2}{*}{ Digital leadership } & $\leq 20$ & 4.30 & 0.42 & \multirow{2}{*}{ Mann-Whitney } & \multirow{2}{*}{0.190} \\
\hline & $>20$ & 4.06 & 0.60 & & \\
\hline
\end{tabular}

* Correlation is statistically significant at level 0.05

** Correlation is statistically significant at level 0.01

Regarding the years of service in Higher Education, we observed that participants with $\leq 20$ years of service exercise statistically significantly more transformational leadership, while participants with> 20 years of service exercise statistically significantly more passive leadership ( $\mathrm{p}<0.05)$ (Table 6).

Regarding the years of service in administrative positions, the participants with $\leq 9$ years of service in an administrative position exercise statistically significantly less transformational and transactional leadership, exercise statistically significantly more passive leadership, and are statistically significantly less satisfied with the leadership outcome (p <0.05) (Table 7).

Table 7. Leadership Types per Years of Service in Administrative position.

\begin{tabular}{|c|c|c|c|c|c|}
\hline Leadership Types & Admin Years & Mean & SD & Test & P-value \\
\hline \multirow{2}{*}{ Transformational leadership } & $\leq 9$ & 3.85 & 0.28 & \multirow{2}{*}{ Mann-Whitney } & \multirow{2}{*}{$0.007 * *$} \\
\hline & $>9$ & 4.26 & 0.18 & & \\
\hline \multirow{2}{*}{ Transactional leadership } & $\leq 9$ & 3.13 & 0.72 & \multirow{2}{*}{ Mann-Whitney } & \multirow{2}{*}{$0.020 *$} \\
\hline & $>9$ & 4.01 & 0.28 & & \\
\hline Passive to avoid leadership & $\leq 9$ & 1.73 & 0.50 & Mann-Whitney & $0.025^{*}$ \\
\hline \multirow{2}{*}{ Outcome leadership } & $\leq 9$ & 3.85 & 0.17 & \multirow{2}{*}{ Mann-Whitney } & \multirow{2}{*}{$0.010^{*}$} \\
\hline & $>9$ & 4.13 & 0.28 & & \\
\hline \multirow{2}{*}{ Digital leadership } & $\leq 9$ & 4.08 & 0.51 & \multirow{2}{*}{ Mann-Whitney } & \multirow{2}{*}{0.343} \\
\hline & $>9$ & 4.25 & 0.54 & & \\
\hline
\end{tabular}

* Correlation is statistically significant at level 0.05

** Correlation is statistically significant at level 0.01 
Finally, the participants in the theoretical direction were found to exercise statistically significantly more transformational leadership, statistically significantly less passive leadership, and are statistically significantly more satisfied with the outcome of leadership ( $<$ <0.05) (Table 8).

Table 8. Leadership style per Years of Service in Object Direction.

\begin{tabular}{|c|c|c|c|c|c|}
\hline Leadership Types & Subject Field & Mean & SD & Test & P-value \\
\hline \multirow{2}{*}{ Transformational leadership } & Humanities and Social Sciences & 4.35 & 0.05 & \multirow{2}{*}{ Mann-Whitney } & \multirow{2}{*}{$0.000 * *$} \\
\hline & Natural and Applied Sciences & 3.84 & 0.22 & & \\
\hline \multirow{2}{*}{ Transactional leadership } & Humanities and Social Sciences & 4.05 & 0.16 & \multirow{2}{*}{ Mann-Whitney } & \multirow{2}{*}{0.065} \\
\hline & Natural and Applied Sciences & 3.25 & 0.79 & & \\
\hline \multirow{2}{*}{ Passive to avoid leadership } & Humanities and Social Sciences & 1.02 & 0.06 & \multirow{2}{*}{ Mann-Whitney } & \multirow{2}{*}{$0.000 * *$} \\
\hline & Natural and Applied Sciences & 1.87 & 0.40 & & \\
\hline \multirow{2}{*}{ Outcome leadership } & Humanities and Social Sciences & 4.12 & 0.14 & \multirow{2}{*}{ Mann-Whitney } & \multirow{2}{*}{$0.043^{*}$} \\
\hline & Humanities and Social Sciences & 3.95 & 0.33 & & \\
\hline \multirow{2}{*}{ Digital leadership } & Natural and Applied Sciences & 4.40 & 0.28 & \multirow{2}{*}{ Mann-Whitney } & \multirow{2}{*}{0.095} \\
\hline & Humanities and Social Sciences & 4.02 & 0.63 & & \\
\hline
\end{tabular}

* Correlation is statistically significant at level 0.05

** Correlation is statistically significant at level 0.01

\section{4-4- Leadership Outcome}

Regarding Leadership outcome, the possible relationship of different leadership types with leadership outcome is investigated using the Pearson correlation coefficient (Table 9).

Table 9. Correlation Outcome leadership vs Leadership type.

\begin{tabular}{lccc}
\cline { 2 - 4 } & \multicolumn{1}{c}{ Transformational leadership } & Transactional leadership & Passive to avoid leadership \\
\cline { 2 - 4 } & $\mathrm{R}^{1}$ & $\mathrm{R}^{1}$ & $\mathrm{R}^{1}$ \\
\hline \multicolumn{1}{c}{$0.650^{* *}$} & $0.617^{* *}$ & -0.244 \\
\hline${ }^{I}$ Coefficient correlation Pearson & & \\
$*$ Correlation is statistically significant at level 0.05 & & \\
${ }^{* *}$ Correlation is statistically significant at level 0.01 & & &
\end{tabular}

The leadership outcome shows a largely positive and statistically significant correlation with the transformational leadership $(\mathrm{R}=0.650)$ and the transactional leadership $(\mathrm{R}=0.617)$ at the level of $\alpha=0.01$. This means that the high degree of exercise of these leadership types coexists with the effectiveness and satisfaction of exercising leadership. On the contrary, the correlation between Leadership Outcome and Passive - To Avoid Leadership is statistically insignificant.

The appearance of statistically significant correlations provides the background for the application of simple linear regression, in order to determine whether there is a specific dependence of the leadership outcome on each leadership style separately. The multiple regression solution was not preferred due to the strong correlations between the independent variables. In the following regressions, we use the leadership outcome as a dependent variable and each leadership style separately as an independent variable. The relevant table presents the basic parameters $\beta$, R2, and pvalue (Table 9).

Table 10. Outcome leadership according to Leadership style (Simple Linear Regression).

\begin{tabular}{ccccc}
\hline Dependent Variable & $\begin{array}{c}\text { Parameters of Simple } \\
\text { Linear Regression }\end{array}$ & $\begin{array}{c}\text { Transformational } \\
\text { leadership }\end{array}$ & $\begin{array}{c}\text { Transactional } \\
\text { leadership }\end{array}$ & $\begin{array}{c}\text { Passive to avoid } \\
\text { leadership }\end{array}$ \\
\hline \multirow{2}{*}{ Outcome leadership } & Coefficient $\beta$ & 0.594 & 0.255 & -0.133 \\
& $\mathrm{p}$-value & $0.002^{* *}$ & $0.004^{* *}$ & 0.300 \\
& $\mathrm{R}^{2}$ & 0.423 & 0.381 & 0.060 \\
\hline
\end{tabular}

* Influence is statistically significant at level 0.05

** Influence is statistically significant at level 0.01 
As it is obvious, transformational leadership has a positive and statistically significant effect $(\mathrm{p}=0.002<0.05)$ on the leadership outcome, that is, the more applicable this leadership style is, the greater the efficiency and satisfaction of teachers. In fact, this independent variable explains a relatively large percentage of the variability of the leadership outcome $\left(R^{2}=0.423\right)$. The leadership outcome depends statistically significantly on the transaction leadership $(p=0.004$ $<0.05)$. The more leaders apply this leadership style, the more effective and satisfied they are. This independent variable explains $38.1 \%$ of the variability of the leadership outcome $\left(\mathrm{R}^{2}=0.381\right)$. As for Passive Leadership, it does not seem to have a statistically significant influence on leadership outcome (Table 10).

\section{4-5- Required Digital Skills}

At this point, survey participants were asked to record the digital skills they can take advantage of and consider most necessary for a leader. Respondents were able to state more than one choice.

Table 11. Digital skills for a leader.

\begin{tabular}{lccc}
\hline & Digital skills & Frequency (N) & Percentage (\%) \\
\cline { 2 - 4 } & Social Media & 13 & 65 \\
& Web Development and Tools & 9 & 45 \\
Mobile App & 8 & 40 \\
Digital Characteristics & Big Data & 5 & 25 \\
& Cloud Computing & 3 & 15 \\
& ERP Systems & 3 & 15 \\
& Digital Architecture & 1 & 5 \\
& Complex Business Systems & 1 & 5 \\
\hline
\end{tabular}

The widespread digital properties of Social Media, Web Development, and Tools and Mobile App are also the ones that received the most responses (65.0, 45.0 and 40.0\% respectively). However, a significant percentage of respondents can take advantage of and consider Big Data important (25.0\%). Digital architectures and Complex Business Systems are exploitable by a few respondents, while Security Skills were not declared by anyone (Figure 6).

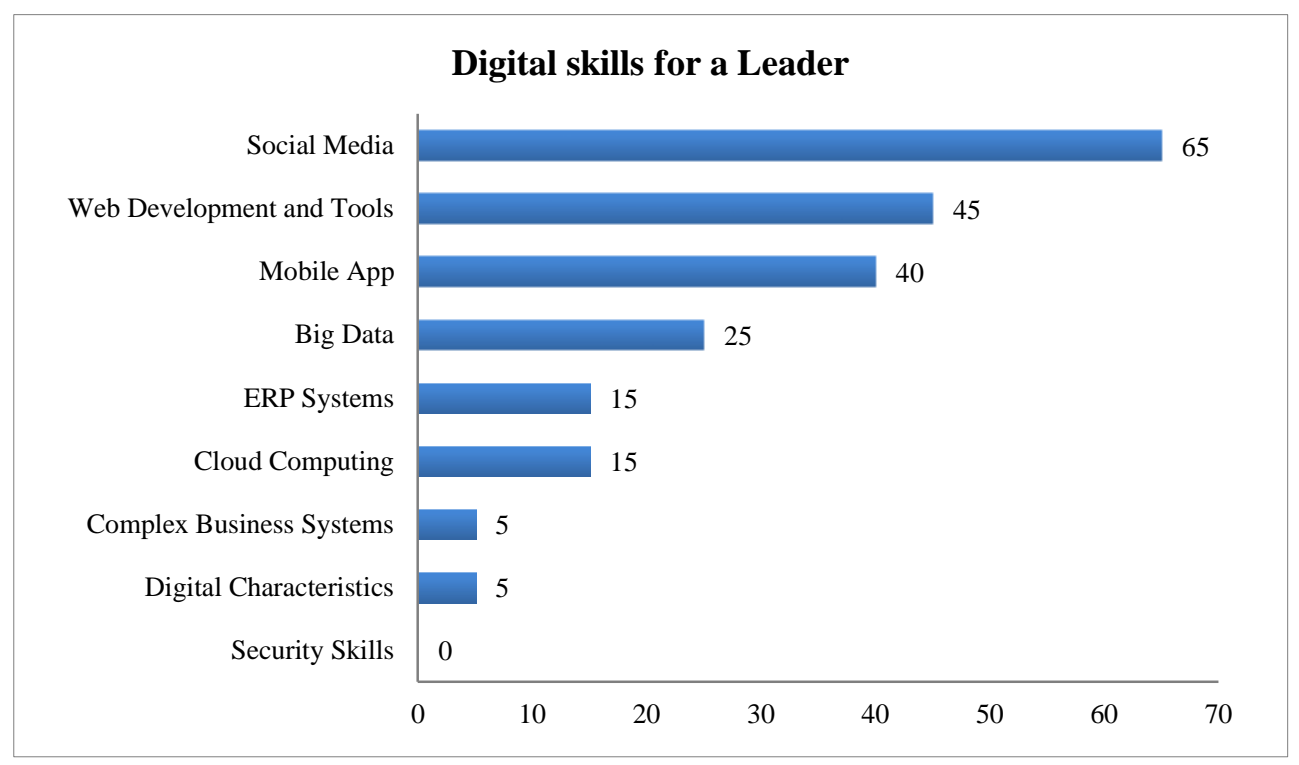

Figure 6. Digital skills that can be exploited by respondents and considered necessary for a leader.

In order to determine whether the demographic characteristics had a statistically significant effect on the reported digital properties, Fisher's exact test was performed. Initially, Big Data was largely reported only by respondents with> 20 years of service in higher education and positive respondents $(\mathrm{p}<0.05)$. Mobile Apps were reported to a much greater extent by participants aged $>60$ years $(\mathrm{p}<0.05)$. Web development and tools were declared to a much greater extent by respondents aged $<=60$ years and respondents with $<=20$ years of service in higher education $(\mathrm{p}<0.05)$. ERP Systems were declared only by respondents with $<=9$ years of service in an administrative position $(\mathrm{p}<0.05)$. Finally, Social 
Media was reported to a much higher extent by participants aged $>60$ years and by participants with $>20$ years of service in higher education $(\mathrm{p}<0.05)$.

Table 12. Number of digital skills per demographic feature.

\begin{tabular}{|c|c|c|c|c|c|}
\hline & Number o & al Skills & SD & Test & P-value \\
\hline \multirow{2}{*}{ Sex } & Male & 2.06 & 1.06 & \multirow{2}{*}{ Mann-Whitney } & \multirow{2}{*}{0.398} \\
\hline & Female & 2.50 & 1.00 & & \\
\hline \multirow{2}{*}{ Age } & $\leq 60$ & 2.08 & 1.24 & \multirow{2}{*}{ Mann-Whitney } & \multirow{2}{*}{0.490} \\
\hline & $>60$ & 2.25 & 0.71 & & \\
\hline \multirow{2}{*}{$\begin{array}{c}\text { Years of Service in Higher } \\
\text { Education }\end{array}$} & $\leq 20$ & 1.70 & 0.95 & \multirow{2}{*}{ Mann-Whitney } & \multirow{2}{*}{$0.035^{*}$} \\
\hline & $>20$ & 2.60 & 0.97 & & \\
\hline \multirow{2}{*}{$\begin{array}{c}\text { Years of Service in } \\
\text { Administrative Position }\end{array}$} & $\leq 9$ & 2.62 & 1.19 & \multirow{2}{*}{ Mann-Whitney } & \multirow{2}{*}{0.114} \\
\hline & $>9$ & 1.83 & 0.84 & & \\
\hline \multirow{2}{*}{ Subject Field } & Humanities and Social Sciences & 1.50 & 0.53 & \multirow{2}{*}{ Mann-Whitney } & \multirow{2}{*}{$0.005 * *$} \\
\hline & Natural and Applied Sciences & 2.89 & 1.05 & & \\
\hline
\end{tabular}

Alternatively, the number of digital attributes that survey participants stated that they could take advantage of and consider important to a leader was examined. On average, respondents stated about 2 of the 9 existing properties. There were participants who declared only 1 but also participants who declared up to 4 . No respondent stated more than 4 attributes. In order to determine whether the demographic characteristics had a statistically significant effect on the number of digital properties declared, non-parametric Mann-Whitney statistical tests were performed.

The results show that a larger number of digital attributes were declared by participants with more than 20 years of service in higher education and by participants with a positive subject $(\mathrm{p}<0.05)$. Next, the relationship of different leadership types with the number of digital attributes reported was investigated.

Table 13. Number of Digital Skills associated with Leadership Style.

\begin{tabular}{|c|c|c|c|c|c|}
\hline & $\begin{array}{c}\text { Transformational } \\
\text { leadership }\end{array}$ & $\begin{array}{c}\text { Transactional } \\
\text { leadership }\end{array}$ & $\begin{array}{l}\text { Passive to avoid } \\
\text { leadership }\end{array}$ & $\begin{array}{c}\text { Outcome } \\
\text { leadership }\end{array}$ & $\begin{array}{c}\text { Digital } \\
\text { leadership }\end{array}$ \\
\hline & $\mathrm{R}^{1}$ & $\mathrm{R}^{1}$ & $\mathrm{R}^{1}$ & $\mathrm{R}^{1}$ & $\mathrm{R}^{1}$ \\
\hline Number of Digital Skills & $-0.466^{*}$ & -0.294 & $0.578 * *$ & -0.339 & -0.168 \\
\hline
\end{tabular}

The results showed a statistically significant negative correlation between the number of reported digital properties and transactional leadership $(\mathrm{R}=-0.466)$ and a statistically significant positive correlation with passive leadership $(\mathrm{R}=$ 578). It is worth mentioning that in the present survey, $85.0 \%$ of respondents stated a low number of digital skills that can be exploited and consider more necessary for a leader. At this point we built a final model (Figure 7) with significant pathways of focal variables. For ease of presentation, parameter estimates for e-skills, and leadership types (Transformational, Transactional, Passive to Avoid and Outcome).

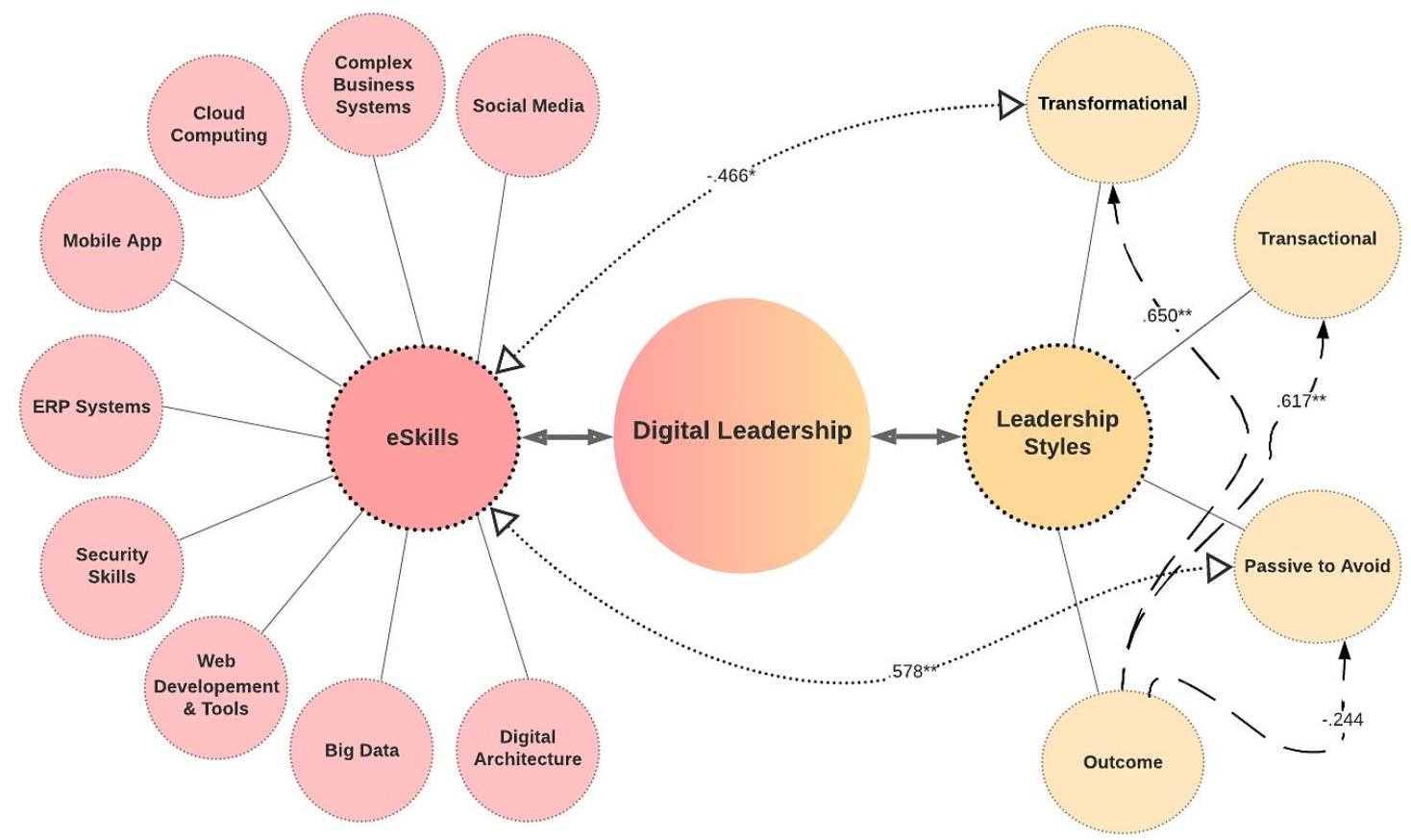

Figure 7. Final model with significant pathways of focused variables. $* p<.05 \mid * * p<.01$. 


\section{5- Conclusion}

Today, digital transformation is an inevitable choice for any organization, regardless of its size or sector. Leaders are faced with new tools daily and make decisions based on the data they have access to. After all, digital transformation is successful in the long run when organizational goals coincide with the need to adopt new digital tools. It is an important responsibility of each leader to guide this strategic alignment with digital culture. However, in order to overcome the challenges posed by digital transformation, leaders are called upon to develop a combination of digital skills, mainly related to the ability to communicate effectively in a digital context, take the initiative and adapt immediately to new situations and behaviors as well as face immediate complex problems. So, universities, as organizations, must transform their practices and continue to adapt in order to be effective in the era of the Internet of Things.

The findings show that the leadership outcome has a strong positive correlation with transformational leadership and a negative correlation with passive - to avoid leadership, confirming that higher transformational leadership implies greater efficiency and satisfaction for employees. A high degree of passive leadership coexists with the corresponding negative degree of implementation of digital leadership. To sum up, it seems that a successful leader who implements transformational leadership as long as is equipped with the appropriate digital skills will be able to be more effective in the way that applies administrative duties in the academic society. Furthermore, a person who is equipped with the appropriate digital skills is more likely to recognize and take advantage of the opportunities that will be presented and also his choices will contribute to the optimal development of a University Institution.

\section{5-1-Future Research}

The academic landscape is now changing due to the digital transformation, leaders are called upon to develop and improve a combination of digital and soft skills, mainly related to the ability to communicate effectively in a new digital context, to create coherence between remote geographical nodes, direct initiative, and adaptability in order to deal with success several complex problems and operating urgent procedures. A study has already been carried out in two other University Institutions of Greece, and the next step is the implementation of a comparative study of the results of a total of three University institutions, which belong to different geographical locations as well as to different administrative regions. Finally, similar research should be done in other Higher Education Institutions in Greece in order to be able to claim that nowadays digital Leaders of higher education institutions in Greece follow the model of transformational leadership and digital transformation.

\section{6- Declarations}

\section{6-1-Author Contributions}

All authors contributed to the design and implementation of the research, to the analysis of the results, and to the writing of the manuscript. All authors read and approved the final manuscript.

\section{6-2-Data Availability Statement}

The data presented in this study are available on request from the corresponding author.

\section{6-3- Funding}

The author(s) received no financial support for the research, authorship, and/or publication of this article.

\section{6-4-Ethical Approval}

Participants gave their written consent to use their anonymous data for statistical purposes. All of them were over 18 years old and voluntarily collaborated without receiving any financial compensation.

\section{6-5- Conflicts of Interest}

The author declares that there is no conflict of interests regarding the publication of this manuscript. In addition, the ethical issues, including plagiarism, informed consent, misconduct, data fabrication and/or falsification, double publication and/or submission, and redundancies have been completely observed by the authors

\section{7- References}

[1] Union, Publications Office of the European. 2020. "European Enterprise Survey on the Use of Technologies Based on Artificial Intelligence: Final Report.” Op.Europa.Eu. Available online: https://op.europa.eu/el/publication-detail/-/publication/f089bbaef0b0-11ea-991b-01aa75ed71a1 (accessed on 4 September 2020).

[2] Cascio, Wayne F., and Ramiro Montealegre. "How Technology Is Changing Work and Organizations." Annual Review of Organizational Psychology and Organizational Behavior 3, no. 1 (March 21, 2016): 349-375. doi:10.1146/annurev-orgpsych041015-062352. 
[3] Yergler, Jeffrey D. “Organizational Culture and Leadership, 4th ed.20121Edgar H. Schein. Organizational Culture and Leadership, 4th Ed.. San Francisco, CA: Jossey - Bass 2010. 400 Pp. (Amazon) Paperback, ISBN: 978 - 0 - 470 - 19060 - 9.” Leadership \& Organization Development Journal 33, no. 4 (June 2012): 421-423. doi:10.1108/01437731211229331.

[4] Kellerman, Barbara, James G. Hunt, B. Rajaram Baliga, H. Peter Dachler, and Chester A. Schriesheim. "Emerging Leadership Vistas." Political Psychology 10, no. 2 (June 1989): 347. doi:10.2307/3791653.

[5] Mango, Emmanuel. "Rethinking Leadership Theories." Open Journal of Leadership 07, no. 01 (2018): 57-88. doi:10.4236/ojl.2018.71005.

[6] Jaser, Zahira. “The Connecting Leader. Aligning Leadership Theories to Managers’ Issues.” Leadership (December 18, 2020): 174271502098118. doi:10.1177/1742715020981188.

[7] Santora, Joseph C. “Book Review: A Force for Change: How Leadership Differs from Management.” Journal of Management 17, no. 1 (March 1991): 218-218. doi:10.1177/014920639101700115.

[8] Avolio, Bruce J., Bernard M. Bass, and Dong I. Jung. "Re-Examining the Components of Transformational and Transactional Leadership Using the Multifactor Leadership.” Journal of Occupational and Organizational Psychology 72, no. 4 (December 1999): 441-462. doi:10.1348/096317999166789.

[9] Antonakis, John, Bruce J Avolio, and Nagaraj Sivasubramaniam. "Context and Leadership: An Examination of the Nine-Factor Full-Range Leadership Theory Using the Multifactor Leadership Questionnaire.” The Leadership Quarterly 14, no. 3 (June 2003): 261-295. doi:10.1016/s1048-9843(03)00030-4.

[10] Bass, Bernard M., and Bruce J. Avolio. “Transformational Leadership and Organizational Culture.” International Journal of Public Administration 17, no. 3-4 (January 1994): 541-554. doi:10.1080/01900699408524907.

[11] Bass, Bernard M. "Does the Transactional-Transformational Leadership Paradigm Transcend Organizational and National Boundaries?” American Psychologist 52, no. 2 (1997): 130-139. doi:10.1037/0003-066x.52.2.130.

[12] McCall, Morgan W. "Leadership and Performance beyond Expectations, by Bernard M. Bass. New York: The Free Press, 1985, 191 Pp.” Human Resource Management 25, no. 3 (1986): 481-484. doi:10.1002/hrm.3930250310.

[13] Koirala, Kamal Prasad. "Successful Leadership Practice in School.” Education and Development 29 (December 1, 2019): 119131. doi:10.3126/ed.v29i0.32576.

[14] Bush, Tony. "The Enduring Power of Transformational Leadership." Educational Management Administration \& Leadership 45, no. 4 (April 21, 2017): 563-565. doi:10.1177/1741143217701827.

[15] Ualesi, Yvonne, and Gillian Ward. "Teachers' Attitudes toward Teaching Science in a New Zealand Intermediate School." Australian Journal of Teacher Education 43, no. 6 (June 2018): 35-49. doi:10.14221/ajte.2018v43n6.3.

[16] Cortellazzo, Laura, Elena Bruni, and Rita Zampieri. “The Role of Leadership in a Digitalized World: A Review." Frontiers in Psychology 10 (August 27, 2019). doi:10.3389/fpsyg.2019.01938.

[17] Emmanuel, Nomah, and Buah Emmanuel. "A Review of the Concept of School-Based Leadership and Underlying Theories of Organizational Management.” International Journal of Innovative Research and Development 7, no. 9 (September 30, 2018). doi:10.24940/ijird/2018/v7/i9/aug18109.

[18] Weber, Ellen, Eva-Helen Krehl, Marion Buettgen, and Karsten Schweikert. "The Digital Leadership Framework: Insights into New Leadership Roles Facing Digital Transformation.” Academy of Management Proceedings 2019, no. 1 (August 1, 2019): 13650. doi:10.5465/ambpp.2019.13650abstract.

[19] Antonopoulou, Hera, Constantinos Halkiopoulos, Olympia Barlou, and Grigorios N Beligiannis. "Leadership Types and Digital Leadership in Higher Education: Behavioural Data Analysis from University of Patras in Greece." International Journal of Learning, Teaching and Educational Research 19, no. 4 (April 30, 2020): 110-129. doi:10.26803/ijlter.19.4.8.

[20] Antonopoulou, Hera, Constantinos Halkiopoulos, Olympia Barlou, and Grigorios N. Beligiannis. "Transition from Educational Leadership to e-Leadership: A Data Analysis Report from TEI of Western Greece.” International Journal of Learning, Teaching and Educational Research 18, no. 9 (September 30, 2019): 238-255. doi:10.26803/ijlter.18.9.13.

[21] Bryant, Scott E. "The Role of Transformational and Transactional Leadership in Creating, Sharing and Exploiting Organizational Knowledge." Journal of Leadership \& Organizational Studies 9, no. 4 (November 2003): 32-44. doi:10.1177/107179190300900403.

[22] Judge, Timothy A., and Ronald F. Piccolo. "Transformational and Transactional Leadership: A Meta-Analytic Test of Their Relative Validity.” Journal of Applied Psychology 89, no. 5 (2004): 755-768. doi:10.1037/0021-9010.89.5.755.

[23] Gellis, Z. D. “Social Work Perceptions of Transformational and Transactional Leadership in Health Care.” Social Work Research 25, no. 1 (March 1, 2001): 17-25. doi:10.1093/swr/25.1.17. 
[24] Howell, Jane M., and Bruce J. Avolio. "Transformational Leadership, Transactional Leadership, Locus of Control, and Support for Innovation: Key Predictors of Consolidated-Business-Unit Performance.” Journal of Applied Psychology 78, no. 6 (1993): 891-902. doi:10.1037/0021-9010.78.6.891.

[25] Lowe, Kevin B., K.Galen Kroeck, and Nagaraj Sivasubramaniam. "Effectiveness Correlates of Transformational and Transactional Leadership: A Meta-Analytic Review of the Mlq Literature.” The Leadership Quarterly 7, no. 3 (September 1996): 385-425. doi:10.1016/s1048-9843(96)90027-2.

[26] Kelly, Eileen P. "Book Reviews: Transformational Leadership: Industry, Military and Educational Impact Bernard M. Bass Lawrence Erlbaum Associates, 1998208 Pp., Paperback, \$29.95.” Journal of Leadership Studies 5, no. 3 (March 1999): 169171. doi:10.1177/107179199900500317.

[27] Hallinger, Philip. "Leading Educational Change: Reflections on the Practice of Instructional and Transformational Leadership." Cambridge Journal of Education 33, no. 3 (November 2003): 329-352. doi:10.1080/0305764032000122005.

[28] Howell, Jane M., and Kathryn E. Hall-Merenda. "The Ties That Bind: The Impact of Leader-Member Exchange, Transformational and Transactional Leadership, and Distance on Predicting Follower Performance.” Journal of Applied Psychology 84, no. 5 (1999): 680-694. doi:10.1037/0021-9010.84.5.680.

[29] Carless, Sally A., Alexander J. Wearing, and Leon Mann. "A short measure of transformational leadership." Journal of business and psychology 14, no. 3 (2000): 389-405. doi:10.1023/a:1022991115523.

[30] "High-Tech Leadership Skills for Europe -Towards an Agenda for 2020 and Beyond Talent for Europe towards an Agenda for 2020 and beyond High-Tech Leadership Skills for Europe." 2017. Available online: http://eskillsscale.eu/fileadmin/eskills_scale/all_final_deliverables/scale_e-leadership_agenda_final.pdf (accessed on August 2020). 